\title{
COMMENTARY
}

\section{The Need for Societal Investment to Improve Cervical Cancer Outcomes in Nigeria: A commentary}

\author{
DOI: $10.29063 /$ ajrh2017/v21i4.2
}

\section{Jonah Musa}

Department of Obstetrics and Gynecology, University of Jos/Jos University Teaching Hospital, Jos, Nigeria ${ }^{1}$; Health Services Research/Visiting Fogarty Fellow to Center for Global Health, Institute for Public Health and Medicine, Feinberg School of Medicine, Northwestern University, Chicago, USA ${ }^{2}$

*For Correspondence: Email: drmusaj@yahoo.com; jonahm@unijos.edu.ng; Jonah.musa@northwestern.edu

\begin{abstract}
Although cervical cancer is a preventable cancer with a well-known natural history, it remains a huge burden in developing countries of sub-Saharan Africa where organized cervical cancer screening services are lacking. Developed countries that have invested on providing organized screening programs have made substantial progress in reducing both incidence and mortality due to cervical cancer. Implementing evidence-based interventions such as human papillomavirus (HPV) vaccination of young girls, early detection and treatment of premalignant conditions of the cervix through conventional Pap cytology, HPV screening or visual aided inspection with acetic acid could significantly reduce incidence of new cases at population level. Societal investment for such preventive services and provision of effective treatment for those diagnosed at early stages will yield economic benefits in reducing premature deaths of women at the prime of their productive lives. From a societal perspective, this should be a priority area for national investment towards the achievement of sustainable development in Nigeria and similar settings in Africa. (Afr J Reprod Health 2017; 21[4]: 17-23).
\end{abstract}

Keywords: Cancer prevention, treatment, society, cervical cancer

\section{Résumé}

Bien que le cancer du col de l'utérus soit un cancer évitable avec une histoire naturelle bien connue, il reste un lourd fardeau dans les pays en développement d'Afrique subsaharienne où les services organisés de dépistage du cancer du col de l'utérus font défaut. Les pays développés qui ont investi dans la mise en place de programmes de dépistage organisés ont fait des progrès substantiels dans la réduction de l'incidence et de la mortalité dues au cancer du col de l'utérus. La mise en œuvre d'interventions fondées sur des données probantes comme la vaccination des jeunes filles contre le papillomavirus humain (VPH), la détection précoce et le traitement des pathologies précancéreuses du col utérin par la cytologie des frottis vaginaux conventionnelle, le dépistage du VPH ou l'inspection visuelle assistée par l'acide acétique pourraient réduire de manière significative la fréquence des nouveaux cas au niveau de la population. L'investissement sociétal pour de tels services préventifs et la fourniture d'un traitement efficace aux personnes diagnostiquées à un stade précoce produiront des bénéfices économiques en réduisant les décès prématurés des femmes quand elles sont dans la fleur de leur vie productive. D'un point de vue sociétal, cela devrait constituer un domaine prioritaire pour l'investissement national en vue de la réalisation du développement durable au Nigeria et dans des contextes similaires en Afrique. (Afr J Reprod Health 2017; 21[4]: 17-23).

Mots-clés: Prévention du cancer, traitement, société, cancer du col de l'utérus

\section{Introduction}

With over half a million new cases of cervical cancer every year, it is the fourth most common cancer affecting women worldwide, after breast, colorectal, and lung cancers ${ }^{1}$. It is also the fourth most common cause of cancer death in women worldwide, causing 266,000 deaths in $2012^{1}$. These statistics suggests an upsurge compared to an earlier report of approximately 454,000 new cases and 200,000 attributable deaths in $2010^{2}$. Developed countries offering comprehensive 
screening programs have recorded a sustained decline in cervical cancer incidence and mortality; however, many developing countries in subSaharan Africa are experiencing an upsurge $e^{2,3}$. Indeed, almost $70 \%$ of the global burden of cervical cancer ${ }^{1}$ falls in areas with lower levels of development. The disparities in cervical cancer incidence and mortality between the developed and developing countries are further evident in the recent global cancer statistics which reported that in sub-Saharan Africa, 34.8 new cases of cervical cancer are diagnosed per 100,000 women annually, and 22.5 per 100,000 women die from the disease ${ }^{1}$, compared to North America with cervical cancer annual incidence of 6.6 per 100,000 women and mortality of 2.5 per 100,000 women. Undoubtedly, these differences could be attributed to the level to which nations have invested to address this disease from a societal perspective. For instance, the National Breast and Cervical Cancer Early Detection Program (NBCCEDP) is an investment by society to ensure that underinsured, low-income women have unfettered access to breast and cervical cancer screening in all US States and has contributed to significant reduction in premature deaths from these cancers ${ }^{4-6}$.

In Nigeria, approximately 11,500 new cervical cancer cases were reported in 2010 compared to about 6,000 in $1980^{2}$. Also, approximately 6,000 deaths were attributed to cervical cancer in 2010 compared to about 3,000 deaths in $1980^{2}$. These statistics suggests an increase in cervical cancer burden as well as mortality in one of Africa's most populous nations. Incidentally, Nigeria ranked the second in the world on the burden of HIV, behind South Africa ${ }^{7}$. The high burden of HIV in Nigeria may be a contributing factor to the growing incidence of cervical cancer, particularly in the younger age group since HIV-mediated immune-suppression has been shown to increase the prevalence of premalignant lesions of the cervix, and the hazard of progression from premalignant to invasive cervical cancer stages is equally higher in an HIV infected population ${ }^{3,8,9}$.

Although the natural history and the etiologic agents for cervical cancer are wellknown ${ }^{10}$ and the anatomical structure and location of the cervix lends itself for effective screening, detection and treatment of pre-cancer stages, this entirely preventable cancer continues to inflict pain, suffering and death among women in Nigeria. It shortens the productive lives of women and has enormous economic consequences for the society! According to the Global cancer report ${ }^{1}$, "cervical cancer can have devastating effects with a very high human, social and economic cost, affecting women in their prime".

In Nigeria, the sad and devastating situation of cervical cancer is not just the high incidence and prevalence of the disease, but of greater concern is the limited infrastructure for effective treatment for invasive cervical cancer particularly when diagnosed in late stages. A recently published data from a federal tertiary academic medical center in Nigeria ${ }^{11}$ showed that majority of these cancers are detected at advanced stages with low survival probability. Additionally, there are several related social factors affecting access to treatment of cervical cancer, even in settings where treatment facilities are available within the country. The National Health Insurance Scheme (NHIS) in Nigeria does not provide coverage for cervical cancer prevention or treatment services and most patients incur heavy out-of-pocket payments ${ }^{12}$. Leaving individuals to bear the cost for such lifesaving preventive and therapeutic services, implicitly limits the utilization of cervical cancer services which could contribute to the late presentation in advanced stages with dismal survival probability. Even in developed societies were treatment facilities are available, cost related factors, health insurance, low levels of health literacy, lack of social support and transportation barriers have limiting effects on patients receiving care in a timely fashion ${ }^{4,13-17}$. It is therefore imperative to look closely at the options for improving cervical cancer health outcomes in Nigeria and similar settings in Africa in the perspective of societal rather than individual investments.

Interventions to improve screening and prevention of new cases, improving health seeking behavior of women, and early detection and treatment of invasive cervical cancer are some of the strategies that could change the current scenario of cervical cancer in Nigeria and similar settings in Africa. Understanding what works well in such settings, 
and the willingness of the society to pay for such interventions are critical elements for achieving sustainable success in improving cervical cancer health outcomes in Nigeria and Africa. This commentary highlights some of these evidencebased interventions to improve cervical cancer prevention and treatment efforts as a justifiable national investment towards sustainable development in Nigeria.

First, the basic tenets of prevention at primary, secondary and tertiary levels are briefly discussed below:

\section{Prevention of new cervical cancer cases}

Perhaps the most cost-effective strategy for reducing cervical cancer incidence and mortality is through primary prevention services. These preventive services include vaccination against the principal causative agents, the high-risk human papillomavirus types (HPV vaccines). Secondary prevention involves investment in cervical cancer screening to detect and treat precancerous cervical abnormalities which if left undetected and untreated could progress to invasive cancer stages. Screening could be done using conventional pap cytology, HPV screening, visual inspection with acetic acid or a combination of screening strategies as recommended by the WHO guidelines depending on availability of resources ${ }^{18}$.

\section{Vaccination}

Infection with the human papillomavirus (HPV) has been shown to be a necessary component in the causal pathway for the development of cervical cancer $^{19}$. Eight of the HPV high-risk genotypes (HPV 16, 18, 45, 31, 33, 52, 58 and 35) account for more than $90 \%$ of cervical cancer cases. HPV 16 and 18 are the most common accounting for about $70 \%$ of cervical cancer cases worldwide ${ }^{10,20}$. Two vaccines with proven efficacy in protecting young girls against these cancer-causing viruses are currently available. They are an AS04adjuvanted HPV-16/18 vaccine and a HPV$6 / 11 / 16 / 18$ L1 virus-like particle vaccine that protects against two non-oncogenic (HPV 6/ 11), and two oncogenic types (HPV 16 and 18). These vaccines have been shown through randomizedcontrolled trials to have efficacy of approximately
$98 \%$ against HPV 16 and $18^{21,22}$. These vaccines are given preferably to young girls at the approved 3-dose schedule over a 6-month period. This approach has been shown to be a cost-effective strategy in preventing cervical cancer in developed and developing countries ${ }^{23,20}$. These preventive vaccines have been subsidized for use in resourcelimited settings, and a recent modeling of optimal cervical cancer prevention strategies in Nigeria estimated a cost of N7,095 (\$45) for the 3 doses of HPV vaccination ${ }^{24}$. This strategy alone has been shown to reduce cases of cervical cancer from 17.45 per 100,000 women to 6.01 per 100,000 women $^{24}$. Indeed, a recent commentary in Lancet Oncology which states that success of HPV vaccination is now a matter of coverage ${ }^{25}$ explicitly shows how these vaccines could prevent this devastating cancer if society is willing to invest in providing vaccines coverage.

\section{Papanicolau Smear cytology screening}

Cytological examination of cervical cells obtained through Papanicolau (Pap) smear continues to be an effective cervical cancer screening modality and has led to sustained decline in cervical cancer cases in developed countries ${ }^{26}$. In low-resource settings such as Nigeria, such organized screening programs are not available. Pap smears require specialized staining techniques and interpretation by a trained cytopathologist, who are often in short supply in settings such as Nigeria. However, if made available it will cost approximately N3010 (\$16) to have a one-life time cytology test, which can reduce the incidence of cervical cancer to 12.15 per 100,000 women compared with 17.45 per 100,000 women without prevention ${ }^{24}$.

\section{HPV DNA screening}

Understanding the etiologic role of HPV in cervical carcinogenesis has led to the development of sensitive assays that detect the most common oncogenic types in women 30 years and above as a screening strategy for cervical cancer particularly in developed settings. Several randomized controlled trials have demonstrated the superiority of HPV DNA testing compared to conventional cervical Pap cytology in preventing advanced cervical cancer incidence and deaths ${ }^{27,28}$. Indeed, 
recent evidence shows that HPV-based screening provides $60-70 \%$ greater protection against cervical carcinomas compared with cytology ${ }^{29}$ with greater effect seen in women 29 years or older. However, most of the available HPV tests are relatively more expensive compare to Pap test, and appropriate guidelines are needed to help reduce the societal cost of implementing a HPV-screening program in Nigeria. Age-based HPV testing used for triaging equivocal Pap cytology results in younger women and as a primary screening test in older women ( $>29$ years) is expected to be more cost-effective $^{30,31}$. On the average high-risk HPV (Hr HPV) DNA testing costs approximately N4462 per test according to estimation from a costeffectiveness analysis study ${ }^{32}$.

\section{Visual inspection with acetic acid (VIA) and treatment with cryotherapy}

This is one of the most effective cervical cancer prevention strategies recommended by the World Health Organization ${ }^{18}$ to resource limited settings like Nigeria and can easily be implemented, even in rural outreach programs in the country. It can be used as a primary cervical screening and prevention strategy or used to evaluate need for cryotherapy and other forms of treatment in women who have positive HPV test or abnormal Pap cytology test ${ }^{33}$. A recent economic analysis estimated that $\$ 3.0-\$ 7.31$ and $\$ 38$ to $\$ 71$ is required per woman to conduct VIA and to treat those who will need either cryotherapy or loop electro-surgical excision procedure (LEEP), respectively ${ }^{34}$. An earlier study done in a neighboring West African country with similar demographics estimated a national annual program ${ }^{35}$ cost of between 0.6 and 4.0 million US dollars with coverage being the major variable that determines cost. On an individual level, they estimated a cost of $\$ 4.93-\$ 14.75$ and $\$ 47.26$ $\$ 84.48$ per woman for VIA and treatment respectively ${ }^{35}$. The findings in Ghana suggests that a similar national program is feasible and could even be more cost-effective looking at the huge population of women in Nigeria who could benefit from this preventive strategy. It is therefore pertinent for government and society to invest on saving the lives of women from this preventable cancer as a cost-saving intervention compared to the future cost of treating invasive cervical cancer, premature mortality, and associated disabilities.

Looking at the targeted interventions for the primary prevention of cervical cancer discussed above, it seems that investing in HPV vaccination and increasing coverage for the WHO VIA "screen-and-treat" strategy will go a long way in stopping the potential cervical cancer epidemic in Nigeria. Optimization modeling ${ }^{24}$ done in Nigeria equally suggested that within the budget constraint, vaccination and cervical cancer screening are costeffective strategies for cervical cancer prevention in Nigeria.

Although, primary prevention will help in preventing new cases of cervical cancer, early detection and optimal treatment of new cancer cases improves survival probability.

\section{Early detection and effective treatment of invasive cervical cancer}

Early detection of cervical cancer cases offers much better treatment opportunities aimed at cure and improving overall cancer survival. To achieve this, health literacy through education of women on the disease is required. Other requirements include training of health personnel on early diagnosis of cervical cancer cases and improving the skills and proficiency of doctors on surgical treatment modality for early cervical cancer stages as well as ability to administer chemo radiation.

\section{Education of women on the disease to improve their health seeking behavior}

Health seeking behavior is critical both for achieving preventive and curative objectives of any health intervention program. Deliberate and welldirected efforts at raising cervical cancer awareness for young girls and mothers to seek primary prevention services are key interventions for sustainable success in cervical cancer prevention and treatment efforts. This will also help to increase the health literacy on cervical cancer risk factors, symptoms and how to access relevant services in the community. Studies have supported the value of health literacy in improving the ability of women with cervical cancer to seek and receive treatment in a timely fashion ${ }^{16}$. 
Investing and partnering with communities for mass media campaigns on radio, television and newspaper publications, design and production of Information, Education and Communication materials on risk factors, symptoms and treatment of cervical cancer will help in realizing this objective.

\section{Training of doctors on early diagnosis of cervical cancer}

Detection of cervical cancer at early stages offers tremendous opportunities for curative treatment that have been shown to improve overall survival probability at a much lower cost to society compared to treatment at advanced cancer stages of the disease. Data from Jos, Nigeria revealed significant survival probability for early cervical cancer stages compared to advanced stages even after controlling for other factors ${ }^{11}$.

\section{Provision of evidence-based treatment for early cervical cancer cases such as early surgical intervention (Hysterectomy), adjuvant chemo radiation}

Treatment of early cervical cancer cases with surgical hysterectomy and adjuvant chemo radiation therapy where indicated have been shown to improve cervical cancer survival and quality of life ${ }^{36,37}$ of patients suffering this disease.

\section{Conclusion and Policy Recommendation}

In conclusion cervical cancer is entirely a preventable disease and society should see the economic benefit of investing its resources on preventive services such as HPV vaccination, effective screening services for early detection and treatment of precancerous conditions, and to offer effective treatment for those diagnosed at early stages to optimize survival and overall quality of life of women. Developing regional centers of excellence in cervical cancer prevention, early detection and treatment in Nigeria will be a worthwhile investment and will greatly reduce the huge economic losses due to premature mortality from cervical cancer. From a societal perspective, this should be a priority area for national investment towards the achievement of sustainable development in Nigeria and similar settings in Africa.

\section{Acknowledgment}

I acknowledge the contributions of Neil Jordan, $\mathrm{PhD}$, and Dustin French, PhD, of the Center for Health care studies, Northwestern University, USA, for knowledge and understanding the role of health economics and health care financing in population health outcomes. I also appreciate their constructive edits and comments on the initial draft of this paper. The NIH/Fogarty International Center grant \#1D43TW009575 supports my doctoral studies in health services research at Northwestern University, Chicago, USA. The contents of this paper are the sole responsibility of the author and do not necessarily represents the official views of NIH Fogarty International Center and the National Cancer Institute.

\section{References}

1. International Agency for Research on Cancer/World Health Organization press release (2013). Latest world cancer statistics. Global cancer burden rises to 14. 1 million new cases in 2012: Marked increase in breast cancers must be addressed. 2013. Available at: $\quad$ https://www.iarc.fr/en/mediacentre/pr/2013/pdfs/pr223_E.pdf

2. Forouzanfar MH, Foreman KJ, Delossantos AM, Lozano R, Lopez AD, Murray CJL and Mohsen Naghavi. Breast and cervical cancer in 187 countries between 1980 and 2010: a systematic analysis. Lancet. 2011 Oct 22;378(9801):1461-84.

3. Awolude O, Morhason-Bello IO, Denny L and Adewole IF. Human papillomavirus infection and related cancers in sub-Saharan Africa: burden and tools for prevention. Vaccine. 2013;31 Suppl 5:vii-x.

4. Ekwueme DU, Uzunangelov VJ, Hoerger TJ, Miller JW, Saraiya M, Benard VB, Hall IJ, Royalty J, Li C and Myers ER. Impact of the National Breast and Cervical Cancer Early Detection Program on Cervical Cancer Mortality Among Uninsured LowIncome Women in the U.S., 1991-2007. Am J Prev Med. 2014;47(3):300-8.

5. Ekwueme DU, Subramanian S, Trogdon JG, Miller JW, Royalty JE, Li C, Guy GP Jr., Crouse W, Thompson $\mathrm{H}$ and Gardner JG. Cost of services provided by the National Breast and Cervical Cancer Early Detection Program. Cancer. 2014;120(16):2604-11.

6. Trogdon JG, Ekwueme DU, Subramanian S and Crouse W. Economies of scale in federally-funded state- 
organized public health programs: results from the National Breast and Cervical Cancer Early Detection Programs. Health Care Manag Sci. 2013;17(4):321-30.

7. GLOBAL REPORT. United Nations Programme on HIV and AIDS (UNAIDS); 2013. Available from: www.unaids.org/sites/default/files/en/media/content assets/documents/epidemiology/2013/gr2013/UNAI DS_Global_Report_2013_en.pdf

8. Denslow SA, Rositch AF, Firnhaber C, Ting J and Smith $\mathrm{J}$. Incidence and Progression of Cervical lesions in Women with HIV: a Systematic Global Review. Int J STD AIDS. 2014; 25(3):163-77.

9. Mogtomo MLK, Malieugoue LCG, Djiepgang C, Wankam M, Moune A and Ngane AN. Incidence of cervical disease associated to HPV in human immunodeficiency infected women under highly active antiretroviral therapy. Infect Agent Cancer. 2009;4:9.

10. Castellsagué X. Natural history and epidemiology of HPV infection and cervical cancer. Gynecol Oncol. 2008;110(3):S4-7.

11. Musa J, Nankat J, Achenbach CJ, Shambe IH, Taiwo BO, Mandong B, Daru PH, Murphy RL and Sagay AS. Cervical cancer survival in a resource-limited setting-North Central Nigeria. Infectious Agents and Cancer; 2016;11(1):15.

12. Ewelukwa O, Onoka C and Onwujekwe O. Viewing health expenditures, payment and coping mechanisms with an equity lens in Nigeria. BMC Health Serv Res. 2013 ;13(1):87.

13. Brookfield KF, Cheung MC, Lucci J, Fleming LE and Koniaris LG. Disparities in survival among women with invasive cervical cancer: a problem of access to care. Cancer. 2009; 115 (1): 166-78.

14. Gunderson CC, Nugent EK, Mcmeekin DS and Moore KN. Distance Traveled for Treatment of Cervical Cancer Who Travels the Farthest, and Does it Impact Outcome? Int $\mathrm{J}$ Gynecol Cancer 2013;23(6):1099-103.

15. Onwujekwe O, Hanson K, Ichoku $\mathrm{H}$ and Uzochukwu B. Financing incidence analysis of household out- ofpocket spending for healthcare : getting more health for money in Nigeria? Int J Health Plann Manage. 2014:174-85.

16. Westin SN, Bustillos D, Gano JB, Fields MM, Coker AL, Sun CC and Ramondetta LM. Social Factors Affecting Treatment of Cervical Ethical Issues and Policy Implications. Obstet Gynecol 2008;111(3):747-51.

17. Subramanian S, Trogdon J, Ekwueme DU, Gardner JG, Whitmire JT and Rao C. Cost of cervical cancer treatment: implications for providing coverage to low-income women under the Medicaid expansion for cancer care. Womens Health Issues. 2010;20(6):400-5.

18. WHO. WHO guidelines for screening and treatment of precancerous lesions for cervical cancer prevention. 2013;

19. Bosch FX, Lorincz A, Muñoz N, Meijer CJLM and
Shah K V. The causal relation between human papillomavirus and cervical cancer. J Clin Pathol. 2002;55(4):244-65.

20. Campos NG, Burger EA, Sy S, Sharma M, Schiffman M, Rodriguez AC, Hildesheim A, Herrero R and Kim JJ. An Updated Natural History Model of Cervical Cancer: Derivation of Model Parameters. Am J Epidemiol 2014;180(5):545-55.

21. Paavonen J, Naud P, Salmerón J, Wheeler CM, Chow SN, Apter D, Kitchener H, Castellsague X, Teixeira JC, Skinner SR, Hedrick J, Jaisamrarn U, Limson G, Garland S, Szarewski A, Romanowski B, Aoki FY, Schwarz TF, Poppe WA, Bosch FX, Jenkins D, Hardt K, Zahaf T, Descamps D, Struyf F, Lehtinen $M$ and Dubin G. For the HPV PATRICIA Study Group. Efficacy of human papillomavirus ( HPV ) $16 / 18$ AS04- adjuvanted vaccine against cervical infection and precancer caused by oncogenic HPV types ( PATRICIA ): final analysis of a doubleblind, randomised study in young women. Lancet. 2009; 374 (9686): 301-14. Erratum in: Lancet. 2010 Sep 25; 376 (9746): 1054.

22. Lehtinen M, Paavonen J, Wheeler CM, Jaisamrarn U, Garland SM, Castellsagué X, Skinner SR, Apter D, Naud P, Salmerón J, Chow SN, Kitchener H, Teixeira JC, Hedrick J, Limson G, Szarewski A, Romanowski B, Aoki FY, Schwarz TF, Poppe WA, De Carvalho NS, Germar MJ, Peters K, Mindel A, De Sutter P, Bosch FX, David MP, Descamps D, Struyf F, Dubin G. For the HPV PATRICIA Study Group. Overall efficacy of HPV-16 / 18 AS04adjuvanted vaccine against grade 3 or greater cervical intraepithelial neoplasia: 4-year end-ofstudy analysis of the randomised, double-blind PATRICIA trial. Lancet Oncol. 2012; 13 (1): 89-99. Erratum in: Lancet Oncol. 2012 Jan; 13(1):e1.

23. Kriekinge G Van, Castellsagué X, Cibula D and Demarteau N. Estimation of the potential overall impact of human papillomavirus vaccination on cervical cancer cases and deaths. Vaccine. 2014;32(6):733-9.

24. Demarteau N, Morhason-Bello IO, Akinwunmi B and Adewole IF. Modeling optimal cervical cancer prevention strategies in Nigeria. BMC Cancer. 2014;14(1):365.

25. Schiffman M and Wacholder S. Success of HPV vaccination is now a matter of coverage. Lancet Oncol. 2012;13(1):10-2.

26. Benard VB, Royalty J, Saraiya M, Rockwell T and Helsel $\mathrm{W}$. The effectiveness of targeting never or rarely screened women in a national cervical cancer screening program for underserved women. Cancer Causes Control. 2015; 26 (5): 713-9.

27. Sankaranarayanan R, Nene BM, Shastri SS, Jayant K, Muwonge R, Budurkh AM, Hingmire S, Malvi SG, Thorat R, Kothari A Chinoy R, Kelkar R, Kane S, Desai S, Keskar VR, Rajeshwarkar R, Panse N and Dinshaw KA. HPV Screening for Cervical Cancer in Rural India. N Engl J Med. 2009;360(14):1385-94.

28. Rijkaart DC, Berkhof J, Rozendaal L, van Kemenade FJ, 
Bulkmans NWJ, Heideman D M, Kenter GG, Cuzick J, Snijders PJ and Meijer CJ. Human papillomavirus testing for the detection of highgrade cervical intraepithelial neoplasia and cancer: final results of the POBASCAM randomised controlled trial. Lancet Oncol. 2012;13(1):78-88.

29. Ronco G, Dillner J, Elfström KM, Tunesi S, Snijders PJF, Arbyn M, Kitchener H, Segnan N, Gilham C, Giorgi-Rossi P, Berkhof J, Peto J, Meijer CJLM, and the International HPV screening working group. Efficacy of HPV-based screening for prevention of invasive cervical cancer: follow-up of four European randomised controlled trials. Lancet. 2014;383 (9916): 524-32.

30. Arbyn M, Buntinx F, Ranst M V, Paraskevaidis E, Martin-Hirsch P and Dillner J. Virologic Versus Cytologic Triage of Women With Equivocal Pap Smears: A Meta-analysis of the Accuracy To Detect High-Grade Intraepithelial Neoplasia. J Natl Cancer Inst. 2004; 96(4):280-93.

31. Goldhaber-Fiebert JD, Stout NK, Salomon J, Kuntz KM and Goldie SJ. Cost-effectiveness of cervical cancer screening with human papillomavirus DNA testing and HPV-16,18 vaccination. J Natl Cancer Inst. 2008;100(5):308-20.

32. Jin XW, Lipold L, Foucher J, Sikon A, Brainard J,
Belinson J, Schramm S, Nottingham K, Hu B and Rothberg MB. Cost-Effectiveness of Primary HPV Testing, Cytology and Co-testing as Cervical Cancer Screening for Women Above Age 30 Years. J Gen Intern Med. 2016;31(11):1338-44.

33. Sankaranarayanan R, Gaffikin L, Jacob M, Sellors J and Robles S. A critical assessment of screening methods for cervical neoplasia. Int $\mathrm{J}$ Gynaecol Obstet. 2005; 89 (2):S4-12.

34. Mvundura M and Tsu V. Estimating the costs of cervical cancer screening in high-burden Sub-Saharan African countries. Int $\mathbf{J}$ Gynecol Obstet. 2014;126(2):151-5.

35. Quentin W, Adu-sarkodie Y, Terris-prestholt F, Legood $\mathrm{R}$ and Opoku BK. Costs of cervical cancer screening and treatment using visual inspection with acetic acid ( VIA ) and cryotherapy in Ghana: the importance of scale.Trop Med Int Health. 2011;16(3):379-89.

36. Backes FJ and Fowler JM. Hysterectomy for the Treatment of Gynecologic Malignancy. Clin Obstet Gynecol 2014;57(1):115-27.

37. Katanyoo K, Praditsitthikorn N, Tangjitgamol S and Manusirivithaya S. Cost-utility analysis of treatments for stage IB cervical cancer. J Gynecol Oncol. 2014;25(2):97-104. 